\title{
A coronary proatherosclerotic marker: Pregnancy-associated plasma protein A and its association with coronary calcium score and carotid intima-media thickness
}

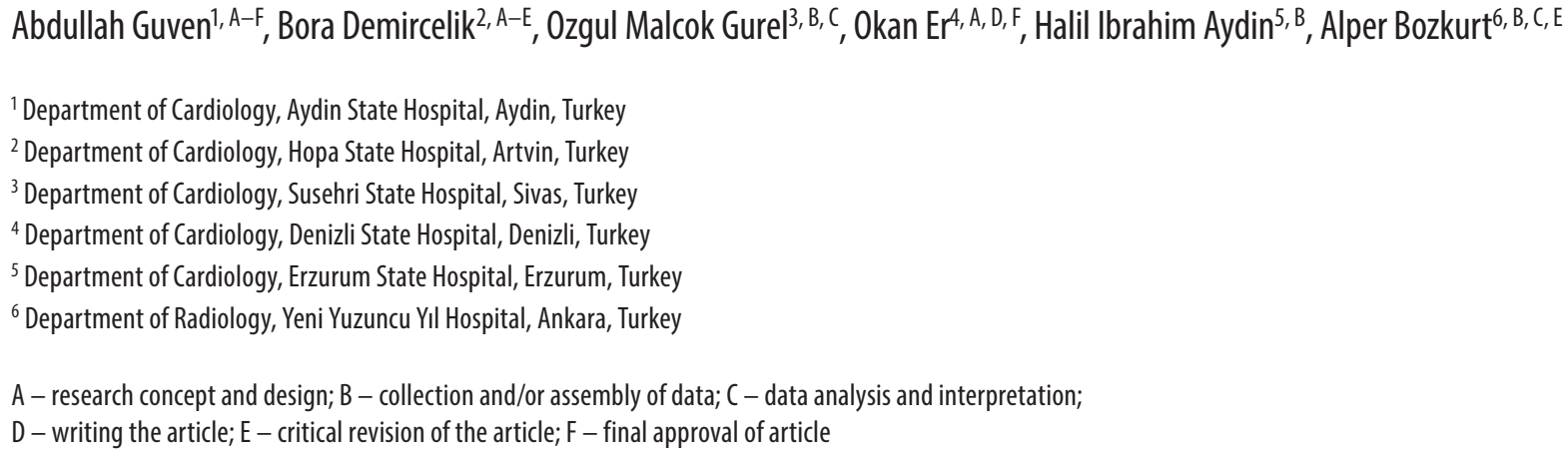

Address for correspondence

Bora Demircelik

E-mail:drdemircelik@yahoo.com

Funding sources

None declared

Conflict of interest

None declared

Received on December 24, 2014

Revised on November 13, 2015

Accepted on March 16, 2016

DOI

10.17219/acem/62225

\begin{abstract}
Background. Atherosclerosis, a chronic inflammatory disorder of the arteries, is responsible for the greatest number of deaths in westernized societies, with numbers increasing at a marked rate in developing countries. Coronary calcium score (CCS), carotid intima-media thickness (CIMT) and pregnancy-associated plasma protein A (PAPP-A) are predictors for the development of atherosclerosis.
\end{abstract}

Objectives. This study was aimed to investigate the relationship between CCS, CIMT and PAPP-A for earlier diagnosis of atherosclerosis.

Material and methods. A total of 99 patients were included in the study. Coronary computerized tomography (CT) angiography was performed on all patients. The calcium scoring technique was performed using a sequential scanning mode. CIMT measurement was done through the area $1 \mathrm{~cm}$ distal of the bulbus arteriosus with carotid Doppler ultrasound. PAPP-A values were analyzed by double immunoenzymatic technique.

Results. Out of 99 patients, 63 were found with coronary atherosclerosis using multislice computed tomography (MSCT) coronary angiography. When the cut-off point for CCS was taken to be 0.40 , the sensitivity of this parameter was $97 \%$ and its specificity was $68.3 \%$. When the cut-off point for CIMT was taken to be 0.60 , the sensitivity and the specificity of these parameters were $75.0 \%$ and $87.3 \%$, respectively, for the right measurements and $75.0 \%$ and $79.4 \%$, respectively, for the left measurements.

Conclusions. This data support the conclusion that PAPP-A, like CCS and CIMT, is a parameter that can be used to detect subclinical atherosclerosis.

Key words: subclinical atherosclerosis, coronary calcium score, carotid intima-media thickness, pregnancy-associated plasma protein A 
Atherosclerosis is the most common cause of mortality and morbidity in the world. Estimation of the presence of atherosclerotic coronary artery disease (CAD) before its clinical presentation is very important in evaluating patients without any or with minimal symptoms. The likelihood of a future cardiovascular event in an individual can be calculated using risk factors, and treatment modalities are being developed to protect against such events. The coronary calcium score (CCS), carotid intima-media thickness (CIMT), and pregnancy-associated plasma protein A (PAPP-A) are predictors of the development of atherosclerosis. ${ }^{1}$

In 1990, Agatston used cardiac scanning with highresolution thin-section computed tomography $(\mathrm{CT})$ and electrocardiography (ECG)-gating to develop a total calcium scoring method. ${ }^{2}$ Today, the total calcium score is calculated with this method using EBT or 64/128- multislice computed tomography (MSCT). Several studies have demonstrated that CCS has great value in predicting cardiovascular outcomes in asymptomatic patients. ${ }^{3}$ A high calcium score increases the likelihood of sensitive plaque, but does not specifically detect sensitive lesions. ${ }^{4}$ It has been reported that the presence of point coronary calcium (smaller than $3 \mathrm{~mm}$ ) more strongly predicts an acute coronary event than the calcium score. ${ }^{5}$

Measurement of CIMT with B-mode ultrasonography (US) has been approved by the American Heart Association (AHA) to assess the risk of atherosclerosis. ${ }^{6}$ The National Cholesterol Education Program Adult Treatment Panel III (NCEP-ATP3) has also stated that the CIMT can be used to assess the risk of CAD, together with other risk determinants. ${ }^{7}$

The timed disintegration of the extracellular matrix (ECM) is an important feature in certain physiological events, including normal development, morphogenesis, and tissue repair. ${ }^{8}$ The dysregulated coordination of this process may lead to myocardial and vascular-wall damage, such as atherosclerosis, left ventricle hypertrophy, heart failure, or aneurism. ${ }^{9}$ Matrix metalloproteinases are the enzymes predominantly responsible for the disintegration of the ECM, and may play a role in the pathogenesis of atherosclerosis and aneurism formation. ${ }^{10,11}$ Pregnancyassociated plasma protein A (PAPP-A) is a high-molecular-weight zinc-binding metalloproteinase, first detected in pregnant women. ${ }^{12}$ It has been used to screen for fetal trisomy in the first trimester of pregnancy. Although it was first used in pregnancy, it has since become a prognostic and diagnostic marker of coronary disease. ${ }^{13}$ PAPP-A is produced in large amounts in eroded and ruptured plaques but in relatively lower amounts in stable plaques. ${ }^{13}$

In 2001, the presence of PAPP-A was shown for the first time in eroded and ruptured atherosclerotic plaques as well as increased levels in patients with acute coronary syndrome. ${ }^{13}$ Several studies have shown that the level of PAPP-A is higher in the presence of more complex and more widespread atherosclerosis in patients with stable CAD. ${ }^{14}$ Higher rates of multivascular disease have been detected on the coronary angiography in people with higher PAPP-A values. ${ }^{15-17}$ Therefore, PAPP-A can be used for early diagnosis and prognosis of patients presenting with acute coronary syndrome, and high PAPP-A levels have been associated with poor prognoses in acute coronary syndrome. ${ }^{18}$ PAPP-A seems to be valuable in predicting the outcomes of patients admitted with high-risk NSTE-ACS or STEMI. ${ }^{19}$

The free fraction of pregnancy-associated plasma protein A (FPAPP-A) was found to be the PAPP-A form released to the circulation in acute coronary syndrome (ACS). We estimated the prognostic value of FPAPP-A vs total PAPP-A (TPAPP-A) concentrations in forecasting death and nonfatal myocardial infarction (combined endpoint) in patients with non-ST-elevation ACS. ${ }^{19}$

In this study we aimed to evaluate the value of PAPP-A in early diagnosis of atherosclerosis and its association with other well-known markers such as CIMT and CCS.

\section{Patients and methods}

\section{Patient selection}

The study population consisted of 99 patients who were clinically referred for noninvasive multislice computed tomography (MSCT) coronary angiography for CAD evaluation. The exclusion criteria for MSCT coronary angiography were acute coronary syndrome, known cardiomyopathy and congestive heart failure (ejection fraction $<50 \%$ ), end-stage renal disease, liver failure, and patients with triglyceride levels above $400 \mathrm{mg} / \mathrm{dL}$. Additionally, patients with hematologic disorders, acute or chronic infection or inflammatory conditions, severe chronic heart failure (New York Heart Association class 3), severe valvular heart disease, and a history of malignancy were excluded from the study. The study protocol was approved by our internal institutional review board.

Height and weight measured at the time of imaging were used to calculate body mass index (BMI). Hypertension was defined as systolic blood pressure $\geq 140 \mathrm{~mm} \mathrm{Hg}$ and/or diastolic blood pressure $\geq 90 \mathrm{~mm} \mathrm{Hg}$ or current antihypertensive treatment. Dyslipidemia was defined as total cholesterol $\geq 200 \mathrm{mg} / \mathrm{dL}$, low density lipoprotein (LDL) cholesterol $\geq 130 \mathrm{mg} / \mathrm{dL}$, high density lipoprotein (HDL) cholesterol $<50 \mathrm{mg} / \mathrm{dL}$, or current lipid-modifying agent treatment. Diabetes mellitus was defined as fasting glucose $\geq 126 \mathrm{mg}$ / /dL or current hypoglycemic treatment. Smoking was classified as current smoking if the patient smoked or quit within the last 30 days and not smoking if the patient never smoked or smoked in the remote past.

\section{MSCT and CCS calculation}

Patients were evaluated based on their pulse rates and clinical status. Those with a heart rate of $\geq 70 / \mathrm{min}$ re- 
ceived 50-100 mg of oral metoprolol succinate or $2.5-5 \mathrm{mg}$ of intravenous metoprolol, according to cardiologist decision. They were included in the procedure when their heart rates became $<70 / \mathrm{min}$. Coronary $\mathrm{CT}$ angiography was performed with a 64-slice consecutive MSCT scan (Philips Brilliance 64; Philips Medical System, Best, the Netherlands).

The calcium scoring technique was performed first, in the sequential scanning mode, after which $100 \mathrm{~mL}$ of iomeprol was infused via a vascular route at a speed of 5-6 mL/s. ECG editing was performed before reconstruction so that the data was not influenced by any arrhythmia.

\section{CIMT measurement}

The patients were examined with carotid ultrasound (US) using a Philips IE 33 echocardiography device with a $10 \mathrm{Mhz}$ linear array transducer. The procedure was performed by 2 physicians. CIMT was measured through an area $1 \mathrm{~cm}$ distal to the bulbus. ${ }^{20}$ Ultrasound images were acquired in semiautomatic mode of the device with dedicated software. Three measurements were performed by each physician separately and their mean values were recorded.

Carotid artery plaque (CAP) was defined as local thickening of the CIMT of $50 \%$ compared to the surrounding vessel wall, an intima media thickness $>1.5 \mathrm{~mm}$, or local thickening $>0.5 \mathrm{~mm}$.

The presence of plaque was recorded as "yes" or "no".

\section{PAPP-A measurement}

Venous blood was drawn from an antecubital vein at the time of hospital admission before MSCT and $1 \mathrm{~mL}$ of serum obtained from this sample was placed in an Eppendorf +or plain tube, and stored at $-80^{\circ} \mathrm{C}$. After the blood samples were restored to room temperature, the PAPP-A levels were analyzed with a double immunoenzymatic technique (sandwich format) using the Beckman Coulter Unicel ${ }^{\circledR}$ Dxl 800 (Brea, California) device with a PAPP-A kit. The results are expressed in $\mathrm{ng} / \mathrm{mL}$. The median serum PAPP-A levels in male subjects [6.85 (undetectable (UD), 24.40) ng/mL] were significantly higher than that of female subjects [3.40 (UD, 36.7) ng/mL]. ${ }^{20}$ According to the manufacturer, the within-run coefficient of variation $(\mathrm{CV})$ was $7.96 \%$ and the detection limit of the method was $0.019 \mathrm{ng} / \mathrm{mL}$.

\section{Data analysis}

The normality of the distributions of the measured values was assessed graphically and with the Shapiro-Wilk test. Descriptive statistics are presented as means \pm standard deviations $(\mathrm{SD})$ or medians (interquartile ranges [IQRs]), depending on the normality of their distribution. Categorical variables are presented as numbers and percentages or in
Table 1. Baseline characteristics of patients in study group

\begin{tabular}{|c|c|c|}
\hline Variables & $\mathrm{N}$ & $\%$ \\
\hline $\begin{array}{l}\text { Sex } \\
\text { male }\end{array}$ & 74 & 74.7 \\
\hline $\begin{array}{l}\text { Carotid artery plaque } \\
\text { yes }\end{array}$ & 43 & 43.4 \\
\hline $\begin{array}{l}\text { Previous history of CAD } \\
\text { no }\end{array}$ & 80 & 80.8 \\
\hline Medical therapy & 5 & 5 \\
\hline Stent & 9 & 9.1 \\
\hline Coronary bypass & 5 & 5 \\
\hline $\begin{array}{l}\text { CAD with MSCT } \\
\text { normal coronary artery } \\
\text { mild stenosis (<50\%) } \\
\text { moderate stenosis (51-69\%) } \\
\text { severe stenosis (> 70\%) }\end{array}$ & $\begin{array}{r}36 \\
29 \\
7 \\
27\end{array}$ & $\begin{array}{r}36.4 \\
29.3 \\
7.1 \\
27.3\end{array}$ \\
\hline $\begin{array}{l}\text { Family history of CAD } \\
\text { yes }\end{array}$ & 24 & 24.2 \\
\hline $\begin{array}{l}\text { Diabetes } \\
\text { yes }\end{array}$ & 17 & 17.2 \\
\hline $\begin{array}{l}\text { Hypertension } \\
\text { yes }\end{array}$ & 39 & 39.4 \\
\hline $\begin{array}{l}\text { Smoking } \\
\text { yes }\end{array}$ & 32 & 32.3 \\
\hline $\begin{array}{l}\text { Hyperlipidemia } \\
\text { yes }\end{array}$ & 32 & 32.3 \\
\hline $\begin{array}{l}\text { CIMT percentile } \\
\quad<25 \% \\
25-75 \% \\
>75 \%\end{array}$ & $\begin{array}{r}62 \\
31 \\
6\end{array}$ & $\begin{array}{r}62.6 \\
31.3 \\
6.1\end{array}$ \\
\hline Statin using & 19 & 19.1 \\
\hline ASA using & 19 & 19.1 \\
\hline
\end{tabular}

\begin{tabular}{|l|c|c|}
\multicolumn{1}{|c|}{ Variables } & Min-Max & $\begin{array}{c}\text { Median (IQR) } \\
\text { /Mean } \pm \text { SD }\end{array}$ \\
\hline Age (years) & $31.0-84.0$ & $52.0(21.0)$ \\
\hline PAPP-A (ng/mL) & $0.80-25.10$ & $2.50(1.38)$ \\
\hline $\begin{array}{l}\text { Coronary calcium score } \\
\text { (agatston) } \\
\text { right CIMT (mm) } \\
\text { left CIMT (mm) }\end{array}$ & $0.0-677.0$ & $15.5(139.8)$ \\
\hline $\begin{array}{l}\text { Total Cholesterol (mg/dL) } \\
\text { HDL (mg/dL) }\end{array}$ & $0.48-0.89$ & $0.64(0.18)$ \\
LDL (mg/dL) & $0.51-0.86$ & $0.62(0.16)$ \\
\hline Triglyceride (mg/dL) & $107.0-304.0$ & $188.5 \pm 53.3$ \\
\hline $\begin{array}{l}\text { Body mass index } \\
\text { (weight - kg/length - } \mathrm{m}^{2} \text { ) }\end{array}$ & $28.0-78.0$ & $46.0(20.0)$ \\
\hline
\end{tabular}

Acetylcalycilic acid (ASA), carotid intima-media thickness (CIMT), coronary artery disease(CAD), multislice computed tomography (MSCT), pregnancy-associated plasma protein A (PAPPA), carotid intima-media thickness (CIMT), high-density lipoprotein (HDL), low-density lipoprotein (LDL).

cross-tables. Differences in continuous variables were calculated with Student's t test or the Mann-Whitney U test, depending on the normality of their distributions. Differences between categorical variables were analyzed with the $\mathrm{c}^{2}$ test or the $\mathrm{c}^{2}$ likelihood ratio. Correlations between PAPP-A, the calcium score, and carotid artery thickness 
were analyzed with Spearman's rank correlation coefficient (r). A receiver-operating characteristic (ROC) curve was drawn to determine the cut-off points for PAPP-A,CCS, and CIMT based on the CT findings, and to calculate the sensitivity and specificity of the parameters. The areas under the curves (AUCs) and 95\% confidence intervals were calculated. A logistic regression model using stepwise regression with the Wald statistic was established to determine the factors that might significantly affect plaque formation in the carotid artery and the degree of risk enhancement by these factors (odds ratio [OR]). Microsoft Excel 2003 and SPSS for Windows v. 15.0 (SPSS Inc., Chicago, USA) were used for the statistical analyses and calculations. $\mathrm{P}<0.05$ was considered to indicate that statistical decisions were significant.
Table 3. Distribution of CAP according to certain groups

\begin{tabular}{|c|c|c|c|c|c|}
\hline \multirow[b]{2}{*}{ Variables } & \multicolumn{2}{|c|}{$\operatorname{CAP}(-)$} & \multicolumn{2}{|c|}{ CAP $(+)$} & \multirow{2}{*}{ p-value } \\
\hline & $\mathrm{n}$ & $\%$ & $n$ & $\%$ & \\
\hline $\begin{array}{l}\text { Family history of CAD } \\
\text { no } \\
\text { yes }\end{array}$ & $\begin{array}{l}42 \\
14\end{array}$ & $\begin{array}{r}56 \\
58.3\end{array}$ & $\begin{array}{r}33 \\
41.7\end{array}$ & $\begin{array}{l}44 \\
24\end{array}$ & 0.841 \\
\hline $\begin{array}{l}\text { Diabetes } \\
\text { no } \\
\text { yes }\end{array}$ & $\begin{array}{r}53 \\
3\end{array}$ & $\begin{array}{r}64.6 \\
17.6\end{array}$ & $\begin{array}{l}29 \\
14\end{array}$ & $\begin{array}{l}35.4 \\
82.4\end{array}$ & $<0.001$ \\
\hline $\begin{array}{l}\text { Hypertension } \\
\text { no } \\
\text { yes }\end{array}$ & $\begin{array}{l}41 \\
15\end{array}$ & $\begin{array}{l}68.3 \\
38.5\end{array}$ & $\begin{array}{l}19 \\
24\end{array}$ & $\begin{array}{l}31.7 \\
61.5\end{array}$ & 0.003 \\
\hline $\begin{array}{l}\text { Smoking } \\
\text { no } \\
\text { yes }\end{array}$ & $\begin{array}{l}39 \\
17\end{array}$ & $\begin{array}{l}58.2 \\
53.1\end{array}$ & $\begin{array}{l}28 \\
15\end{array}$ & $\begin{array}{l}41.8 \\
46.9\end{array}$ & 0.633 \\
\hline $\begin{array}{l}\text { Hyperlipidemia } \\
\text { no } \\
\text { yes }\end{array}$ & $\begin{array}{l}40 \\
16\end{array}$ & $\begin{array}{r}59.7 \\
50\end{array}$ & $\begin{array}{l}27 \\
16\end{array}$ & $\begin{array}{r}40.3 \\
50\end{array}$ & 0.362 \\
\hline
\end{tabular}

\section{Results}

The study included 99 patients, of whom 25 were female (aged 32-86 years, median age 55.0 years [IQR 19.5]) and 74 were male (aged $31-87$ years, median age 51.5 years [IQR 16.3]). The radiological and biochemical data for the patients are listed in Table 1 . Certain characteristics of the patients are illustrated in Table 2 .

The patients with CAP were older than those without CAP, and their PAPP-A, CCS, and CIMT values were also higher (Table 3). CAP was significantly more prevalent in patients with diabetes mellitus (DM) or hypertension (HT) (Table 4).

The prevalence of CAP differed significantly according to the percentile of CIMT $\left(\mathrm{c}^{2}=12.331, \mathrm{p}=0.002\right)$. When we investigated the class(es) in which this difference arose, we found that the differences between the $<25 \%$ CMIT group and the 25\%-75\% CMIT group $\left(c^{2}=8.032\right.$, $\mathrm{p}=0.005)$ and between the $<25 \%$ CMIT and the $>75 \%$ CMIT groups $\left(c^{2}=6.478, p=0.011\right)$ were statistically significant. The difference between the $25 \%-75 \%$ percentile CIMT group and the $>75 \%$ percentile CIMT group was not statistically significant $\left(c^{2}=1.185, \mathrm{p}=0.276\right)$.

PAPP-A, CCS, and CIMT (right and left) were determined and evaluated according to CAD (Table 5). The median PAPP-A, CCS, and left CIMT values were higher in the CAD-positive patients than in the CAD-negative patients $(\mathrm{p}<0.05)$. The median CIMT (right) was higher in the CAD-positive patients than in the CAD-negative patients, but the significance of the difference was borderline $(Z=1.937 ; \mathrm{p}=0.053)$.

When we investigated the correlations between PAPPA, CCS, and CIMT, there was a strong linear correlation between PAPP-A and CCS ( $\mathrm{r}=0.805$; $\mathrm{p}<0.001$ ), moderately strong linear correlations between PAPP$\mathrm{A}$ and right CIMT $(\mathrm{r}=0.532 ; \mathrm{p}<0.001)$ and left CIMT $(\mathrm{r}=0.568 ; \mathrm{p}<0.001)$, and strong linear correlations between CCS and right CIMT $(\mathrm{r}=0.616 ; \mathrm{p}<0.001)$ and left CIMT ( $r=0.676 ; \mathrm{p}<0.001)$. The risk of developing CAP (OR = 6.944) was 6.944 times higher in the patients with DM than in those without DM. This risk was higher in patients with DM (95\% confidence interval [CI]: 1.787-26.98; p = 0.0057). Similarly, the risk of developing CAP $(\mathrm{OR}=2.810)$ was 2.810 times higher in patients with HT than in patients without HT. This risk was at the least 1.151 times higher and at most 6.860 times higher in patients with

Pregnancy associated plasma protein-A (PAPP-A); carotid intima-media thickness (CIMT);

high-density lipoprotein (HDL); low-density lipoprotein (LDL). 
Table 4. PAPPA, coronary calcium score, and CIMT according to coronary artery disease (CAD)

\begin{tabular}{|l|c|c|c|c|c|}
\multirow{2}{*}{\multicolumn{1}{c}{ Variables }} & \multicolumn{2}{c|}{ No } & \multicolumn{2}{c|}{ Yes } & Test statistic \\
\cline { 2 - 6 } & min-max & median (IQR) & min-max & median (IQR) & p-value \\
\hline PAPPA & $0.80-25.10$ & $1.90(1.10)$ & $1.30-24.00$ & $2.80(1.90)$ & 0.001 \\
\hline Coronary calcium score & $0.00-677.00$ & $0.00(44.50)$ & $0.00-3100.00$ & $123.00(239.00)$ & $<0.001$ \\
\hline CIMT right & $0.48-1.13$ & $0.62(0.18)$ & $0.52-0.89$ & $0.70(0.14)$ & 0.053 \\
CIMT left & $0.51-1.00$ & $0.61(0.17)$ & $0.57-1.03$ & $0.71(0.19)$ & 0.013 \\
\hline
\end{tabular}

Pregnancy-associated plasma protein A (PAPPA); carotid intima-media thickness (CIMT). subclinical atherosclerosis, it can be concluded that high PAPP-A, CCS, and CIMT are associated with subclinical atherosclerosis.

To our knowledge, this is the first study to evaluate PAPP-A levels on subclinical atherosclerosis with CCS and CIMT. Thus, this study

HT, with a probability of $95 \%(\mathrm{p}=0.023)$. None of the other risk factors considered to affect the development of CAP increased or reduced the risk of CAP in this study ( $p>0.05)$.

The sensitivity and specificity of PAPP-A, CCS, and CIMT were determined by recoding vascular stenosis as (1) normal or (2) stenotic, depending on the MSCT results. When the MSCT results for vascular stenosis (normal or stenotic) were determined using the PAPP-A values, the area under the ROC curve (AUC) was 0.813 (95\% CI: 0.729-0.897), which was significantly higher than 0.50 ( $\mathrm{p}<0.001$ ). Therefore, the most appropriate cut-off point for PAPP-A that could be used to predict the MSCT results was $2.35 \mathrm{ng} / \mathrm{mL}$. Thus, a PAPP-A value > 2.35 indicates vascular stenosis and a value $<2.35$ indicates a normal vascular structure. When the cut-off point for PAPP-A was taken to be 2.35 , the sensitivity and specificity of this parameter were $94.3 \%$ and $63.9 \%$, respectively.

When the MSCT results for vascular stenosis (normal or stenotic) were determined using CCS, AUC was 0.836 (95\% CI: $0.758-0.913$ ), which was higher than 0.50 ( $\mathrm{p}<0.001$ ). Therefore, the most appropriate cut-off point for CCS that could be used to predict the MSCT results was 0.40 . Thus, CCS > 0.40 indicates vascular stenosis and CCS $<0.40$ indicates a normal vascular structure. When the cut-off point for CCS was taken to be 0.40 , the sensitivity of this parameter was $97 \%$ and its specificity was $68.3 \%$.

When the MSCT results for vascular stenosis (normal or stenotic) were determined using CIMT (right, left), AUC was 0.852 (95\% CI: 0.773-0.932) for right CIMT and 0.848 (95\% CI: 0.766-0.931) for left CIMT, which were both higher than 0.50 ( $\mathrm{p}<0.001)$. Therefore, the most appropriate cut-off point for CIMT that could be used to predict the MSCT results was 0.60 . Thus, CIMT > 0.60 indicates vascular stenosis and CIMT $<0.60$ indicates a normal vascular structure. When the cut-off point for CIMT was taken to be 0.60 , the sensitivity and the specificity of these parameters were $75.0 \%$ and $87.3 \%$, respectively, for the right measurements and $75.0 \%$ and $79.4 \%$, respectively, for the left measurements.

\section{Discussion}

In this study, we showed that PAPP-A, CCS, and CIMT were significantly higher in $\mathrm{CAP}(+)$ patients than in CAP $(-)$ patients. If CAP $(+)$ patients are considered to have showed PAPP-A's stronger relationship with subclinical atherosclerosis.

Even though CCS and CIMT were known to be risk factors for subclinical atherosclerosis, the most important result of our study is to show that PAPP-A is also a risk factor for subclinical atherosclerosis.

Atherosclerosis develops during the lifespan of an individual and involves a number of steps: respectively, activation of the endothelium and recruitment of immune cells; monocyte differentiation and foam cell formation; development of fibrotic plaques due to the death of foam cells and migration and proliferation of smooth muscle cells (SMCs); plaque rupture and thrombosis. Both the innate and adaptive immune response in atherosclerosis is organized by a range of cytokines, which regulate all stages of the disease. ${ }^{21}$

Noninvasive imaging techniques can be used to detect and monitor preclinical atherosclerosis in human arteries. The use of CIMT and CCS to detect subclinical atherosclerosis has become a topical issue and many studies of this subject have been conducted. However, the results for the use of PAPP-A are so far contentious, and as yet, it has no place in clinical practice.

In daily practice, carotid US is used to explore the lesion obstructing the carotid artery. The measurement of CIMT using B-mode US has been approved by the AHA for the evaluation of atherosclerotic risk. ${ }^{6}$ Research has shown that CIMT is associated with myocardial infarction (MI), stroke, CVD, and death. ${ }^{22}$ Therefore, the use of CIMT as a marker for atherosclerosis is supported. ${ }^{23}$ Carotid plaque is also valuable in assessing the risk of CVD, with an even higher positive predictive value than CIMT. $^{23}$

In this study, when the combined effects of the atherosclerotic risk factors on CAP formation were investigated, only the presence of DM and HT increased the risk of CAP, and no other factors did so. Although the prevalence of atherosclerosis is expected to be lower in females than in males, the incidence of CAP did not differ between the sexes in this study. This might be attributable to the advanced age of the women participating in the study. Other studies have demonstrated that the difference between females and males in the incidence of CAD disappears after menopause. ${ }^{24}$

Our study showed that older subjects had a higher incidence of CAP, which is consistent with studies that have 
shown an increase in atherosclerosis with age. Previous series of studies have proved the association of increased CIMT and the presence of carotid plaques with CAD. Ultrasonographic assessment of CIMT and carotid plaques is a valid and proven method for the early evaluation of cardiovascular disease. ${ }^{25}$ This corroborates the hypothesis that CAP is an indicator of atherosclerosis, which is also consistent with the literature.

Several studies have demonstrated that high CCS is an indicator of atherosclerosis and that it is a valuable parameter for estimating cardiovascular outcomes in asymptomatic patients. ${ }^{2,26} \mathrm{CAC}$ is always associated with mural atheromatous plaque. ${ }^{3}$

Our findings support the results of earlier studies that showed higher CCSs in patients with CAP $(+) .{ }^{27}$ In the present study, the prevalence of CAP was higher in patients with CAD and highest in those with advanced CAD when detected by MSCT. This indicates an association between the presence of CAP and the severity of CAD, which is consistent with the literature.

A study by Elesber et al. showed that patients who had ruptured plaques had higher serum PAPP-A levels than patients who had stable plaques. ${ }^{28}$ However, Bayes-Genis et al. stated that PAPP-A levels are higher in the presence of more extensive and complex atherosclerosis in patients with stable CAD. ${ }^{13}$

A higher rate of multivascular disease was detected with coronary angiography in patients with higher PAPP-A values. ${ }^{14}$ It has also been reported that increased PAPP-A levels in patients with chronic stable angina pectoris predict all-cause mortality. ${ }^{16}$ Although PAPP-A has previously been reported as a predisposing factor for atherosclerosis, later studies have reported that PAPP-A is produced as compensatory in atherosclerosis. ${ }^{14,29}$ However, in both cases, PAPP-A is increased in atherosclerosis, so PAPP-A can be used as an indicator of subclinical atherosclerosis. In the present study, PAPP-A values were high in patients with CAP. Because the presence of CAP provides information about the presence of atherosclerosis, it can be concluded that PAPP-A is high in cases of atherosclerosis, which is consistent with the literature.

In this study, we found a strong linear correlation between PAPP-A and CCS, only a moderately positive linear correlation between PAPP-A and CIMT, and a strong linear correlation between CCS and CIMT. This information supports the conclusion that PAPPA, like CCS and CIMT, is a parameter that can be used to detect subclinical atherosclerosis.

The cut-off values for PAPP-A, CCS, and CIMT were determined according to the presence or absence of CAD. Based on the results of this study, the most appropriate cut-off value for PAPPA is $2.35 \mathrm{ng} / \mathrm{mL}$. The sensitivity and specificity of this value in detecting CAD were $94.3 \%$ and $63.9 \%$, respectively. When an Agatston score of 0.4 was taken as the cut-off value for CCS, the sensitivity and specificity of CCS in detecting CAD were $97.2 \%$ and $68.3 \%$, re- spectively. When $0.6 \mathrm{~mm}$ was taken as the cut-off value for the right CIMT, the sensitivity and specificity of the right CIMT in detecting CAD were $75 \%$ and $87.3 \%$, respectively. When $0.6 \mathrm{~mm}$ was taken as the cut-off value for the left CIMT, the sensitivity and specificity of this parameter in detecting CAD were $75 \%$ and $79.4 \%$, respectively.

In the process of selecting patients for stress tests and planning treatment strategies, these cut-off values could be used as reference parameters. For example, if PAPPA is $>2.35 \mathrm{ng} / \mathrm{mL}$, CIMT is over $0.6 \mathrm{~mm}$, and CCS is over 0.4 in an asymptomatic patient with a moderate risk of CAD, then acetylsalicylic acid, beta blockers and statins are the options, of which one or more of them can be chosen as initial therapy. If the patient has atypical symptoms and the above-mentioned values are high, then the patient can be assigned to a stress test. If the patient is symptomatic and the above-mentioned values are high, then the patient can be assigned to conventional imaging methods without a stress test. In this way, the rates of false negatives and false positives of the stress tests can be reduced.

This study was conducted in a single center with 99 patients included. Multicenter studies in larger patient populations are required to clarify the values discussed above and to develop appropriate therapy modalities. In the analysis of CCS, the high-dose exposure of radiation due to MSCT is a disadvantage. For this reason, determining the CVD score seems to be a better parameter than CCS. Another limitation is that we measured total PAPP-A, not the free form. J. Lund et al. suggested that the free form of PAPP-A is a stronger predictor. ${ }^{18}$ The venous blood samples were obtained only once at clinical presentation and no other samples were taken for follow-up. We therefore cannot exclude whether follow-up PAPP-A levels have a better predictive value or not.

Another limitation of this study is that PAPP-A values also could not be evaluated in patients taking statins. The effects of statins may reduce the plaque burden, thus statins could also be an effect on PAPP-A levels. Whether statins could downregulate PAPP-A levels is unclear. A total of 19 of our patients were using statins. Because of the small number for evaluation, we thought this would not be healthy.

Statins have been widely used in cardiovascular diseases for their versatile function such as regulation of lipid level, anti-inflammation and endothelium repair. However, it remains unknown whether stains have established an effect in reducing PAPP-A. Miedema et al. reported that high-dose atorvastatin $(80 \mathrm{mg} / \mathrm{d})$ could decrease the serum PAPP-A in ACS patients after one month treatment. ${ }^{30}$

In conclusion, PAPP-A elevations in circulation play an important role in the diagnosis of subclinical atherosclerosis. Although the sample size of our study was sufficient, there is a need for large-scale, randomized trials for clinical reflection. Larger clinical trials would enhance the diagnostic capability of this novel biomarker. 


\section{References}

1. Consuegra-Sanchez L, Fredericks S, Kaski JC. Pregnancy-associated plasma protein-A (PAPP-A) and cardiovascular risk. Atherosclerosis. 2009;203(2):346-352.

2. Agatston AS, Janowitz WR, Hildner FJ, Zusmer NR, Viamonte M Jr, Detrano R. Quantification of coronary artery calcium using ultrafast computed tomography. J Am Coll Cardiol. 1990;15(4):827-832.

3. Raggi $P$, Callister TQ, Cooil B, et al. Identification of patients at increased risk of first unheralded acute myocardial infarction by electron-beam computed tomography. Circulation. 2000;101:850-855.

4. Wexler L, Brundage B, Crouse J, et al. Coronary artery calcification: pathophysiology, epidemiology, imaging methods, and clinical implications. A statement for health professionals from the American Heart Association. Writing Group. Circulation. 1996;94: $1175-1192$.

5. Ehara S, Kobayashi Y, Yoshiyama M, et al. Spotty calcification typifies the culprit plaque in patients with acute myocardial infarction: An intravascular ultrasound study. Circulation. 2004;110:3424-3429.

6. Smith SC Jr, Greenland P, Grundy SM. AHA conference proceedings. Prevention conference V: Beyond secondary prevention: Identifying the high-risk patient for primary prevention: Executive summary. American Heart Association. Circulation. 2000;101:111-116.

7. Stork S, van den Beld AW, von Schacky C, Angermann CE, Lamberts SW, Grobbee DE, Bots ML. Carotid artery plaque burden, stiffness, and mortality risk in elderly men: A prospective, population-based cohort study. Circulation. 2004;110:344-348.

8. Nagase H, Visse R, Murphy G. Structure and function of matrix metalloproteinases and TIMPs. Cardiovasc Res. 2006;69:562-573.

9. Newby AC. Dual role of matrix metalloproteinases (matrixins) in intimal thickening and atherosclerotic plaque rupture. Physiol Rev. 2005;85:1-31.

10. Visse R, Nagase H. Matrix metalloproteinases and tissue inhibitors of metalloproteinases: Structure, function, and biochemistry. Circ Res. 2003;92:827-839.

11. Libby P. Molecular bases of the acute coronary syndromes. Circulation. 1995;91:2844-2850.

12. Oxvig C, Sand O, Kristensen T, Kristensen L, Sottrup-Jensen L. Isolation and characterization of circulating complex between human pregnancy-associated plasma protein-A and proform of eosinophil major basic protein. Biochim Biophys Acta. 1994;1201:415-423.

13. Bayes-Genis A, Conover CA, Overgaard MT, et al. Pregnancy-associated plasma protein A as a marker of acute coronary syndromes. N Engl J Med. 2001;345:1022-1029.

14. Cosin-Sales J, Christiansen M, Kaminski P, et al. Pregnancy-associated plasma protein $A$ and its endogenous inhibitor, the proform of eosinophil major basic protein (proMBP), are related to complex stenosis morphology in patients with stable angina pectoris. Circulation. 2004;109:1724-1728.

15. Cosin-Sales J, Kaski JC, Christiansen M, et al. Relationship among pregnancy associated plasma protein-A levels, clinical characteristics, and coronary artery disease extent in patients with chronic stable angina pectoris. Eur Heart J. 2005;26:2093-2098.
16. Heeschen C, Dimmeler S, Hamm CW, Fichtlscherer S, Simoons $M L$, Zeiher AM. Pregnancy-associated plasma protein-A levels in patients with acute coronary syndromes: Comparison with markers of systemic inflammation, platelet activation, and myocardial necrosis. J Am Coll Cardiol. 2005;45:229-237.

17. Elesber AA, Conover CA, Denktas AE, et al. Prognostic value of circulating pregnancy-associated plasma protein levels in patients with chronic stable angina. Eur Heart J. 2006;27:1678-1684.

18. Lund J, Qin QP, Ilva T, et al. Circulating pregnancy-associated plasma protein A predicts outcome in patients with acute coronary syndrome but no troponin I elevation. Circulation. 2003;108:1924-1926.

19. Lund J, Wittfooth S, Qin QP, et al. Free vs total pregnancy associated plasma protein A (PAPP-A) as a predictor of 1-year outcome in patients presenting with non-ST-elevation acute coronary syndrome. Clin Chem. 2010;56(7):1158-1165.

20. Abdurrahman $\mathrm{C}$, Mustafa $\mathrm{SD}$, Tamer $\mathrm{Cl}$, et al. Reference interval of pregnancy-associated plasma protein-A in healthy men and nonpregnant women. Journal of Cardiology. 2013;61:128-131.

21. McLaren JE, Michael DR, Ashlin TG, Ramji DP. Cytokines, macrophage lipid metabolism and foam cells: Implications for cardiovascular disease therapy. Prog Lipid Res. 2011;50:331-347.

22. Chambless LE, Heiss G, Folsom AR, et al. Association of coronary heart disease incidence with carotid arterial wall thickness and major risk factors: The Atherosclerosis Risk in Communities (ARIC) Study, 1987-1993. Am J Epidemiol. 1997;146:483-494.

23. Stein $\mathrm{JH}$, Korcarz CE, Hurst RT, et al. Use of carotid ultrasound to identify subclinical vascular disease and evaluate cardiovascular disease risk: A consensus statement from the American Society of Echocardiography Carotid Intima-Media Thickness Task Force. Endorsed by the Society for Vascular Medicine. J Am Soc Echocardiogr. 2008;93:189-190.

24. Grundy SM, Balady GJ, Criqui MH, et al. Primary prevention of coronary heart disease: guidance from Framingham: A statement for healthcare professionals from the AHA Task Force on Risk Reduction. American Heart Association. Circulation. 1998;97:1876-1887.

25. Limbu YR, Rajbhandari R, Sharma R, et al. Carotid intima-media thickness (CIMT) and carotid plaques in young Nepalese patients with angiographically documented coronary artery disease. Cardiovasc Diagn Ther. 2015;5(1):1-7.

26. Rumberger JA. Using noncontrast cardiac CT and coronary artery calcification measurements for cardiovascular risk assessment and management in asymptomatic adults. Vasc Health Risk Manag. 2010;6:579-591.

27. Shaw LJ, Raggi P, Schisterman E, Berman DS, Callister TQ. Prognostic value of cardiac risk factors and coronary artery calcium screening for all-cause mortality. Radiology. 2003;228:826-833.

28. Elesber AA, Conover CA, Denktas AE, et al. Prognostic value of circulating pregnancy-associated plasma protein levels in patients with chronic stable angina. Eur Heart J. 2006;27(14):1678-1684.

29. Bayes-Genis A, Schwartz RS, Lewis DA, et al. Insulin-like growth factor binding protein-4 protease produced by smooth muscle cells increases in the coronary artery after angioplasty. Arterioscler Thromb Vasc Biol. 2001;21:335-341.

30. Miedema MD, Conover CA, MacDonald H, et al. Pregnancy-associated plasma protein-A elevation in patients with acute coronary syndrome and subsequent atorvastatin therapy. Am J Cardiol. 2008;101:35-39. 